\title{
The influence of the viscosity of the ointment vehicles magisterial topical preparations, on the speed transfer of biologically active substances
}

\author{
Adrian Glogowski ${ }^{1}$, Justyna Kolodziejska ${ }^{2}$, \\ Michal K. KolodziejCZYK ${ }^{2}$, Marian M. ZGOdA ${ }^{3}$
}

1 "NEUCA" S.A. Pharmaceutical Wholesaler, ul.Batalionow Chlopskich 91a, 25-671 Kielce, Poland

${ }^{2}$ Department of Drug Form Technology, Chair of Applied Pharmacy, Medical University of Lodz, ul. Muszynskiego 1, 90-151 Lodz, Poland

${ }^{3}$ Extramural Doctoral Study Center, Chair of Applied Pharmacy, Medical University of Lodz, ul. Muszynskiego 1, 90-151 Lodz, Poland

\section{ARTICLE INFO}

Received 30 June 2015

Accepted 28 September 2015

\section{Keywords:}

ointments, viscosity, viscous elasticity,

volatile component loss.

\begin{abstract}
The aim of this study was to analyze the morphological parameters (viscosity, viscous elasticity and the rate of volatile component loss) of salicylic and boric acid-containing magisterial formulae (ointments). Moreover, the effects of these parameters on the diffusion rate of a therapeutic agent (salicylic acid) to an in vitro external compartment were analyzed. Finally, the applicatory properties of the ointments prepared by way of a conventional technique (in a mortar) and with the aid of an unguator, were compared. The rheological parameters of the analyzed ointments suggest that the preparations made with an aid of an unguator, irrespective of the physicochemical characteristics of their vehicles, are characterized by higher values of diffusion coefficient (D). In addition, conventionally-prepared formulae containing salicylic were shown to be characterized by better viscous elasticity. Surprisingly, irrespective of the preparation technique, the ointments based on an absorptive vehicle (containing lanolin) were characterized by similar viscous elasticity. The rate of volatile (water) component loss from ointments containing a $3 \%$ solution of boric acid suggests that such formulae lose no more than $2.3 \%$ of their mass when exposed at $37^{\circ} \mathrm{C}$. Therefore, the viscosity of such ointments applied onto a patient's skin should remain relatively stable.
\end{abstract}

\section{INTRODUCTION}

Ointments constitute the predominant (the main) category of prescription preparations prepared in community pharmacies and hospitals $[1,2,8,11,14,17,19-21]$. It should be noted that the clinical effectiveness of these dosage forms is determined by the solubility of the biologically active substances in vehicle, as well as their rheological parameters $[3,5,6,9,13,18,22]$. In ointments, the physicochemical properties of the vehicles, especially the relationship between solid and liquid phase, determine their viscosity ( $\mathrm{y}$ ), and, therefore, modulate the magnitude of diffusion coefficient (D) as calculated by the Einstein-Smoluchowski equation $(\mathrm{D}=\mathrm{k} \cdot \mathrm{T} / 6 \pi \mathrm{r} \eta)[4,10,15]$.

The aim of this study was to analyze the morphology of magisterial formulae prepared in selected pharmacies

\begin{tabular}{l} 
* Corresponding author \\
e-mail: adrian.glogowski@koia.kielce.pl \\
tel.: +48413654507 \\
\hline
\end{tabular}

located within Swietokrzyskie Province (Poland). As part of the study, viscosity, viscous elasticity and the rate of volatile component loss were marked, and the influence of these parameters on the diffusion rate of salicylic acid and boric acid to an in vitro external compartment was analyzed $[7,23]$. In this work, for the interpretation of the mass exchange process at the phase boundary, the method of agar plates containing the marker of diffusion was employed. The above study method was used to compare the ointment prepared by way of a conventional technique (in a mortar) and by way of the aid of an unguator [12].

\section{EXPERIMENTAL}

\section{Ointment vehicles}

White petrolatum (Vaselinum album; PPF Hasco Lek S.A.), yellow petrolatum (Vaselinum flavum; PPF Hasco Lek S.A.), eucerin (Eucerini; PPF Eucerini Works, 
Pharmaceutical Laboratory S.J.), anhydrous lanolin (Lanolinum anhydricum; PPF Eucerini Works, Pharmaceutical Laboratory S.J.).

\section{Therapeutic agents - ingredients of magisterial preparations}

Urea $\left(\mathrm{CO}\left(\mathrm{NH}_{2}\right)_{2}\right)$, precipitated sulfur (Sulfur precipitatum), boric acid ( $\mathrm{H}_{3} \mathrm{BO}_{3}$, Acidum boricum), salicylic acid $\left(\mathrm{C}_{6} \mathrm{H}_{4}(\mathrm{COOH}) \mathrm{OH}\right.$, Acidum salicylicum $)$ - "Amara" Pharmaceutical Works Cracow.

The molecular radius ( $\mathrm{r}$ ) of boric acid was calculated by the equation $\mathrm{r}=\sqrt[3]{3 V / 4 \pi}=2.23096 \cdot 10^{-8} \mathrm{~cm}\left(1 \mathrm{~A}^{\circ}=1 \cdot 10^{-8} \mathrm{~cm}\right)$, upon estimating its molecular volume $\left(\Sigma \Delta V=28.0 \mathrm{~cm}^{3} / \mathrm{mol}\right)$, using the Fedors method (14).

The molecular radius ( $\mathrm{r}$ ) of salicylic acid was calculated by the equation $\mathrm{r}=\sqrt[3]{3 V / 4 \pi}=3.321099 \cdot 15^{8} \mathrm{~cm}\left(1 \mathrm{~A}^{\circ}=1 \cdot 10^{-8} \mathrm{~cm}\right)$, upon estimating its molecular volume $\left(\Sigma \Delta V=91.5 \mathrm{~cm}^{3} / \mathrm{mol}\right)$, using the Fedors method (14).

The model therapeutic agent (salicylic acid) represented an inhomogeneous system. Herein, the micronization of salicylic acid resulted in a degradation of its primary crystallographic structure, and a tendency towards the adhesion of molecular contact surfaces.

\section{Equipment}

Cone-plate digital rheometer (DV-III, version 3.0; Brookfield) with a "Rheocalc for Windows" software, mechanical stirrer (R50D; CATM Zipperer GmbH), unguator (CITO UNGUATOR e/s; EPRUS, Bielsko-Biała), digital caliper enabling measurement of the diffusion area (CD-15CP Absolute Digimatic Caliper; Mitutoyo), analytical scale (WPS 36/S; Radwag).

To determine the correlation equations describing diffusion in the course of time, Microsoft Excel 2010 was used. This observation was confirmed by the approximation formulas describing the kinetics of water loss from the ointments based on lanolin-containing absorptive vehicles at $p=0.05$. The formulas that describe the abovementioned process with the highest values of correlation coefficients (r) are presented in Table 10.

\section{Vehicles used in magisterial formulae (ointments) prepared within the Świętokrzyskie Macroregion}

The number of magisterial topical formulae (ointments) was estimated as a percentage of all prescriptions filled in 2009-2012, by the selected community pharmacies from Swietokrzyskie Province (Pharmacy in Blizyn, "Cefarm" Pharmacy in Kielce, Pharmacy in Gorno, "Warszawska" Pharmacy in Kielce, Pharmacy in Zagnansk, Pharmacy in Daleszyce, Pharmacy in Kielce, "Zagorska" Pharmacy in Kielce, Pharmacy in Bodzentyn, Pharmacy in Bieliny, and Pharmacy in Chmielnik I and II). Although the percentage of magisterial formulae in the total number of filled prescriptions turned out to be region-specific, it did not exceed $8.78 \%$ (mean $3.50 \%$ ). The vehicles used in the magisterial formulae included: lanolin $(44.81 \%)$, yellow petrolatum $(25.96 \%)$, white petrolatum $(27.54 \%)$, eucerin $(20.15 \%)$, cholesterol ointment base (26.01\%), "hascobaza" (13.15\%), "lekobaza" (1.97\%), zinc paste (2.68\%), lard $(0.12 \%)$, solid paraffin $(0.35 \%)$ and zinc ointment base $(0.19 \%)$.

\section{Magisterial formulae (ointments) containing} boric acid and salicylic acid

The study included the three magisterial topical formulae (ointments) containing salicylic and boric acid that were most often prepared in the community pharmacies mentioned above. Compositions of these formulae are presented in Table 1.

Table 1. Composition of magisterial formulae prepared with a conventional technique (in a mortar) and with an aid of an unguator for the purpose of morphological examination

\begin{tabular}{|l|c|c|c|c|c|c|}
\hline \multirow{2}{*}{\multicolumn{1}{c|}{ Ingredients }} & \multicolumn{7}{c|}{ Formulations } \\
\cline { 2 - 8 } & No. 1 & No. 2 & No. 3 & No. 4 & No. 5 & No. 6 \\
\hline 1. Eucerin & $\bullet$ & $\bullet$ & $\bullet$ & $\bullet$ & $\bullet$ & $\bullet$ \\
\hline 2. Anhydrous lanolin & $\bullet$ & $\bullet$ & + & + & + & + \\
\hline 3. Yellow petrolatum & + & + & + & + & + & + \\
\hline 4. Zinc oxide & $\bullet$ & $\bullet$ & $\bullet$ & + & $\bullet$ & $\bullet$ \\
\hline 5. Precipitated sulfur & $\bullet$ & + & $\bullet$ & $\bullet$ & $\bullet$ & $\bullet$ \\
\hline 6. Urea & $\bullet$ & $\bullet$ & + & $\bullet$ & $\bullet$ & $\bullet$ \\
\hline 7. Salicylic acid & 10.0 & 5.0 & 10.0 & $\bullet$ & $\bullet$ & $\bullet$ \\
\hline 8. Boric acid solution (3\%) & $\bullet$ & $\bullet$ & $\bullet$ & 20.0 & 33.3 & 10.0 \\
\hline
\end{tabular}

The magisterial formulae (100 g each) were prepared according to the prescription and in line with the technological pharmacopeial recommendations "lege artis" stated in Polish Pharmacopoeia X (Ph.Pol X) [16]. To compare their applicatory properties, the ointments were prepared with two different methods: using a conventional technique (i.e. in a mortar) and with an aid of an unguator.

\section{Determination of rheological parameters of the magisterial formulae}

The viscosity of the ointments (Table 1) was determined with a cone-plate digital rheometer (DV-III, version 3.0; Brookfield) connected to a bath thermostat (PGW E-1; Medingen). Viscous elasticity of the ointments was measured with an extensometer with polycarbonate top and bottom plates [7].

\section{Determination of the therapeutic agent release to an external compartment}

An agar hydrogel ( $2 \mathrm{~g}$ of agar per $100 \mathrm{~cm}^{3}$ of deionized water) was prepared on a Petri dish, with iron(III) chloride $\left(\mathrm{FeCl}^{3}\right)$ or methyl orange (an indicator of $\mathrm{pH}_{\mathrm{aH}+}$ ) being added. Holes of an appropriate diameter were cut in the solidified hydrogel with an aid of a cork borer, and filled with the salicylic acid-containing ointments. The rate of diffusion was determined on the basis of a color reaction between salicylic acid (ligand) and $\mathrm{Fe}^{3+}$ (transition metal, forming a violet color complex), or between the hydronium ion $\left(\mathrm{H}_{3} \mathrm{O}^{+}\right)$and the indicator structure (change of color to red). The size (diameter) of a color zone within the agar hydrogel reflects as a function of time $(t, \mathrm{~min})$, the diffusion rate of a therapeutic agent $\left(\mathrm{P}=\pi \mathrm{r}^{2}\right)$ released to hydrogel from an ointment.

\section{Determination of the rate of volatile component loss from an ointment}

The rate of volatile component (water) loss from magisterial preparations containing a $3.0 \%$ solution of boric 
acid, was determined by way of the gravimetric method, at $37^{\circ} \pm 0.2^{\circ} \mathrm{C}$, as described elsewhere [23].

\section{RESULTS AND DISCUSSION}

The viscosities of the magisterial preparations determined at a constant shear rate (Table 2) constituted the basis for calculating the theoretical diffusion coefficient (D) of a therapeutic agent to an external compartment. The Einstein-Smoluchowski equation (15) $\mathrm{D}=\mathrm{k} \cdot \mathrm{T} / 6 \pi \mathrm{r} \cdot 1 / \mathrm{h}$ was substituted with the Baltzman constant $\left(1.380650 \cdot 10^{-23}\right.$ $\mathrm{J} / \mathrm{K}), \mathrm{T}$ - temperature in Kelvin $\left(304.75^{\circ} \mathrm{K}\right), \mathrm{r}$ - molecular radius of a therapeutic agent $\left(\mathrm{r}=3.31099 \cdot 10^{-8} \mathrm{~cm}\right.$ for salicylic acid and $\mathrm{r}=2.28096 \cdot 10^{-8} \mathrm{~cm}$ boric acid; $1 \mathrm{~A}^{\circ}=1 \cdot 10^{-8} \mathrm{~cm}$ ), and transformed into the following forms: $\mathrm{D}=6.3967 \cdot 10^{-13}$ $(\mathrm{J} / \mathrm{m}) \cdot 1 / \mathrm{y}$ and $\mathrm{D}=9.4935 \cdot 10-13(\mathrm{~J} / \mathrm{m}) \cdot 1 / \mathrm{y}$ for salicylic and boric acid, respectively.

This enabled us to calculate the diffusion coefficients (D) for therapeutic agents contained in the magisterial formulae presented in Table 1. The D-values for the analyzed preparations are shown in Table 2. The data presented in Table 2 suggest that the magisterial formulae prepared with an aid of an unguator were characterized by higher values of diffusion coefficient (D), albeit within the same order of magnitude as for the conventionally-prepared formulae. The fact that the ointments containing aqueous molecular solution of boric acid $(3.0 \%)$ showed similar values of the diffusion coefficient (D), irrespective of the preparation technique, seems particularly interesting in the context of their applicatory properties. In contrast, the salicylic acid-containing ointments prepared with the two methods differed markedly in terms of their D-coefficients.

Table 2. Viscosity parameters of magisterial preparations determined at constant shear stress and calculated diffusion coefficients of salicylic and boric acid

\begin{tabular}{|c|c|c|c|c|}
\hline $\begin{array}{c}\text { Magisterial } \\
\text { formulae }\end{array}$ & \begin{tabular}{|c|} 
Shear stress \\
$\left(\mathrm{N} / \mathrm{m}^{2}\right)$
\end{tabular} & $\begin{array}{c}\text { Shear rate } \\
(1 / \mathrm{s})\end{array}$ & $\begin{array}{l}\text { Viscosity } \\
(\mathrm{mPa} \cdot \mathrm{s})\end{array}$ & $\begin{array}{c}\text { Diffusion } \\
\text { coefficient } \\
\left(\mathrm{M}^{2} / \mathrm{s}\right)\end{array}$ \\
\hline $\begin{array}{l}\text { No. } 1- \\
\text { unguator }\end{array}$ & 21.9 & 0.20 & 109340 & $5.8503 \cdot 10^{-15}$ \\
\hline No. 2 - "- & 26.2 & 0.20 & 131208 & $4.8752 \cdot 10^{-15}$ \\
\hline No. 3 - " - & 160.8 & 0.20 & 804146 & $7.9547 \cdot 10^{-16}$ \\
\hline No. 4 - " - & 112.5 & 0.20 & 562604 & $1.6874 \cdot 10^{-15}$ \\
\hline No. $5-$, & 118.3 & 0.20 & 591430 & $1.6051 \cdot 10^{-15}$ \\
\hline No. $6-{ }_{-,}-$ & 101.4 & 0.20 & 506940 & $1.8727 \cdot 10^{-15}$ \\
\hline $\begin{array}{l}\text { No. } 1 \text { - } \\
\text { conventional tech. }\end{array}$ & 35.4 & 0.20 & 176932 & $3.6153 \cdot 10^{-15}$ \\
\hline No. 2 - " - & 28.4 & 0.20 & 142142 & $4.5002 \cdot 10^{-15}$ \\
\hline No. 3 - " - & 206.8 & 0.20 & 1033760 & $6.1878 \cdot 10^{-16}$ \\
\hline No. 4 - " - & 185.3 & 0.20 & 926408 & $1.0247 \cdot 10^{-15}$ \\
\hline No. 5 - " - & 158.6 & 0.20 & 793212 & $1.1968 \cdot 10^{-15}$ \\
\hline No. 6 - " - & 144.5 & 0.20 & 722638 & $1.3137 \cdot 10^{-15}$ \\
\hline
\end{tabular}

Subsequently, the viscous elasticity of the same formulae prepared by way of the two alternative methods was determined with an aid of an extensometer (Tables 3 and 4). The data presented in Tables 3 and 4 suggest that the salicylic acid-containing ointments prepared through a conventional technique (in a mortar) were characterized by significantly greater viscous elasticity, than were the ointments based on the same prescription formula, but prepared by way of an unguator. In turn, the ointments containing a 3\% solution of boric acid showed similar viscous elasticity irrespective of the preparation technique. However, it should be noted that the formulae no. 4 and 6 , both prepared with an aid of an unguator, were characterized by a slightly better viscous elasticity than were their analogues prepared by way of a conventional technique.

The aforementioned findings were confirmed by the use of approximation equations. These describe the relationships between an increase in the surface area, $\Delta \mathrm{S}\left(\mathrm{S}_{\mathrm{t}}-\mathrm{S}_{\mathrm{o}}, \mathrm{cm}^{2}\right)$, and applied strain, $\Delta \mathrm{m}\left(\mathrm{m}_{\mathrm{t}}-\mathrm{m}_{\mathrm{o}}, \mathrm{g}\right): \Delta \mathrm{S}\left(\mathrm{cm}^{2}\right)=\mathrm{f}(\Delta \mathrm{m}, \mathrm{g})$ at $\mathrm{p}=0.05$ (Table 5). Analysis of the approximation formulas presented in Table 5, namely the values of elastic constant $\mathrm{K}$ (regression coefficient $\mathrm{b}$ ), brings about a confirmation that the conventionally-prepared ointments containing salicylic acid were characterized by greater viscous elasticity than were their analogues prepared with an aid of an unguator. Noticeably, the approximation equations: $y=a+b \cdot x$ and $\log y=a+b \cdot \log x$ (a logarithmic form of an exponential equation $y=a \cdot x^{b}$ ) describing the viscous elasticity of the conventionally-made formulae, were characterized by the highest values of correlation coefficients (Table 5). In the case of the formulae prepared with an aid of an unguator, apart from the equations mentioned above, high values of correlation coefficients were also found for the equations: $\log y=a=b x, y=a+b \cdot \log x$ and $\log y=a+b \cdot 1 / x$. This likely reflected differences in the structure of vehicles used in formulae prepared with an unguator and those of conventionally-made preparations.

The data obtained during the complex analyses of viscosity and viscous elasticity of the same magisterial formulae (ointments) prepared with the two alternative techniques, enabled us to estimate the diffusion rate of salicylic acid to the external compartment (2.0\% agar hydrogel). For such work, we used a color indicator, i.e. the violet complex of $\mathrm{Fe}^{3+}$ with the salicylic acid ligand, as well as methyl orange changing its color in response to changes in the activity of the hydronium ion $\mathrm{pH}_{\mathrm{aH}}{ }^{+}$during the diffusion of salicylic acid into the hydrogel. The data on the increase in the surface area of the released salicylic acid $\left(\mathrm{S}=\pi \mathrm{r}^{2}, \mathrm{~mm}^{2}\right)$ as a function of time (t, min), is presented Tables 6 and 7 . The abovementioned process was described with approximation equations at $p=0.05$. The regression coefficients of the equations characterized by the highest values of correlation coefficients (r) are presented in Table 8. The data presented in Tables 6 and 7 point to a relatively stable diffusion rate of salicylic acid. This is confirmed not only by its similar diffusion areas (AS, $\left.\mathrm{mm}^{2}\right)$, but also by its constant diffusion rates $(k)$ (regression coefficients b).

The data on the diffusion rate of salicylic acid to agar hydrogel (i.e. diffusion of the hydronic ion $\mathrm{H}_{3} \mathrm{O}^{+}-\mathrm{pH}_{\mathrm{aH}}{ }^{+}$), determined with a novel indicator (methyl orange), suggests that, irrespective of the D-coefficient magnitude, the process of mass transfer across a phase boundary is characterized by a kinetics o $(y=a+b x)$; however, the values of correlation coefficient (r) were higher for a logarithmic form of the exponential equation $y=a \cdot x^{\mathrm{b}}(\log y=a+b$ $\cdot \log x$ ). This likely results from different densities of the formulae (ointments), irrespective of their preparation technique, and especially from extremely different levels 
of hydrophilic-lipophilic balance (HLB) within either ointment's vehicle and external hydrogel compartment.

The release of salicylic acid from ointments prepared by way of the two alternative methods was described through $y=a+b \cdot c x$ type equations, and through a logarithmic form of the exponential equation $y=a \cdot x^{\mathrm{b}}$ (Table 8); all the equations were characterized by high values of correlation coefficients (r). The values of the regression coefficients of the approximation equations presented in Table 8 suggest that the methyl orange-based analytical model was characterized by relatively higher values of diffusion constant $\mathrm{k}$ (only a dissociated molecule of salicylic acid was released from the ointment).

Lack of rapid loss of volatile component (i.e. water) from a formula constitutes a prerequisite of effective pharmacotherapy with ointments based on absorptive vehicles (e.g. anhydrous lanolin, Lanolinum anhydricum). Herein, the loss of water results in a change of viscosity at a phase boundary, which is reflected by a marked decrease in the diffusion coefficient magnitude $(\mathrm{D}=\mathrm{kT} / 6 \pi \mathrm{r} \eta)$. This argument stimulated us to analyze the degree of volatile component (water) loss from magisterial formulae containing various amounts of $3 \%$ boric acid and prepared with an aid of two different techniques. The results presented in Table 9 suggest that, irrespective of the preparation technique, the loss of volatile components (water) from the preparations containing $10.0 \%$ and $20.0 \%(\mathrm{v} / \mathrm{v})$ of $3 \%$ boric acid did not exceed $1.5 \%$ (Table 9). In contrast, significant differences were found in the degree of water loss from the ointment containing $33.3 \%(\mathrm{v} / \mathrm{v})$ of $3 \%$ boric acid. Here, while the loss of water from the ointment no. 5 , when prepared with the aid of an unguator, did not exceed $0.8 \%$, the analogous parameter for the formula prepared by way of a conventional method (i.e. in a mortar) amounted to $2.3 \%$ (Table 9). These findings suggest that the use of an unguator promotes greater dispersion and better binding of water, by the vehicle component, lanolin (an emulsifier of a w/o system).

This observation was confirmed by the approximation formulas describing the kinetics of water loss from the ointments based on lanolin-containing absorptive vehicles at $p=0.05$. The formulas that describe the abovementioned process with the highest values of correlation coefficients (r) are presented in Table 10.

The rate of volatile (water) component loss from ointments containing 3\% solution of boric acid suggests that such formulae lose no more than $2.3 \%$ of their mass when exposed at $37^{\circ} \mathrm{C}$. Therefore, the viscosity of such ointments applied onto patient's skin should remain relatively stable for $3 \mathrm{~h}(180 \mathrm{~min})$, which is reflected by the stable value of the diffusion coefficient (D).

Table 3. Magisterial formulae prepared with an aid of an unguator. Viscous elasticity of the formulae $\left(\mathrm{S}_{\mathrm{t}}-\mathrm{S}_{\mathrm{o}}, \mathrm{cm}^{2}\right)$ presented as mean values from $3-5$ measurements at $25.0 \pm 0.1^{\circ} \mathrm{C}$

\begin{tabular}{|c|c|c|c|c|c|c|c|c|}
\hline No. & $\underset{(\mathrm{min})}{\mathrm{t}}$ & $\begin{array}{c}\mathrm{m}_{\mathrm{t}}-\mathrm{m}_{0} \\
(\mathrm{~g})\end{array}$ & $\begin{array}{c}\text { No. } 1 \text { "u" } \\
\mathrm{S}_{1}-\mathrm{S}^{\circ} \\
\left(\mathrm{cm}^{2}\right) \\
\end{array}$ & $\begin{array}{l}\text { No. } 2 \text { "u" } \\
\mathrm{S}_{1}-\mathrm{S}_{\circ} \\
\left(\mathrm{cm}^{2}\right) \\
\end{array}$ & $\begin{array}{c}\text { No. } 3 \text { "u" } \\
\mathrm{S}_{1}-\mathrm{S}_{\circ} \\
\left(\mathrm{cm}^{2}\right) \\
\end{array}$ & $\begin{array}{c}\text { No. } 4 \text { "u" } \\
\mathrm{S}_{\mathrm{t}}-\mathrm{S}_{\mathrm{o}} \\
\left(\mathrm{cm}^{2}\right)\end{array}$ & $\begin{array}{l}\text { No. } 5 \text { "u" } \\
\mathrm{S}_{1}-\mathrm{S}_{\circ} \\
\left(\mathrm{cm}^{2}\right) \\
\end{array}$ & $\begin{array}{c}\text { No. } 6 \text { "u" } \\
\mathrm{S}_{\mathrm{t}}-\mathrm{S}_{\mathrm{o}} \\
\left(\mathrm{cm}^{2}\right)\end{array}$ \\
\hline 1 & 15 & 10 & 0.8008 & 1.0108 & 0.6652 & 0.3928 & 0.5832 & 1.7584 \\
\hline 2 & 30 & 20 & 3.0772 & 1.6644 & 1.1752 & 0.5388 & 0.6896 & 2.4826 \\
\hline 3 & 45 & 50 & 5.4932 & 3.0772 & 2.0940 & 0.8012 & 0.7848 & 2.7318 \\
\hline 4 & 60 & 100 & 6.5924 & 4.9044 & 2.2180 & 1.2248 & 3.2672 & 4.3096 \\
\hline 5 & 75 & 200 & 8.6332 & 8.8080 & 2.3548 & 4.3628 & 5.6520 & 7.5693 \\
\hline 6 & 90 & 250 & 9.41834 & 10.1424 & 3.1380 & 5.4620 & 6.8136 & 9.2080 \\
\hline 7 & 120 & 300 & 9.8892 & 11.1844 & 3.6800 & 6.6236 & 8.9980 & 10.5896 \\
\hline & & & $\begin{array}{c}\mathrm{m}_{\mathrm{o}} \text { of a plate } \\
=27.3970 \mathrm{~g} \\
\mathrm{~S}_{\mathrm{o}}=\mathrm{nr}^{2}= \\
4.7116 \mathrm{~cm}^{2} \\
\text { Salicylic acid }\end{array}$ & $\begin{array}{c}\mathrm{m}_{\mathrm{o}} \text { of a plate } \\
=26.6150 \mathrm{~g} \\
\mathrm{~S}_{\mathrm{o}}=\mathrm{nr}^{2}= \\
4.7116 \mathrm{~cm}^{2} \\
\text { Salicylic acid }\end{array}$ & $\begin{array}{c}\mathrm{m}_{\mathrm{o}} \text { of a plate } \\
=27.0820 \mathrm{~g} \\
\mathrm{~S}_{\mathrm{o}}=\mathrm{nr}^{2}= \\
5.9364 \mathrm{~cm}^{2} \\
\text { Salicylic acid }\end{array}$ & $\begin{array}{c}\mathrm{m}_{\mathrm{o}} \text { of a plate } \\
=26.6630 \mathrm{~g} \\
\mathrm{~S}_{\mathrm{o}}=\mathrm{nr}^{2}= \\
4.7116 \mathrm{~cm}^{2} \\
\text { Boric acid }\end{array}$ & $\begin{array}{c}\mathrm{m}_{\mathrm{o}} \text { of a plate } \\
=27.5620 \mathrm{~g} \\
\mathrm{~S}_{\mathrm{o}}=\mathrm{nr}^{2}= \\
4.5216 \mathrm{~cm}^{2} \\
\text { Boric acid }\end{array}$ & $\begin{array}{c}\mathrm{m}_{\mathrm{o}} \text { of a plate } \\
=26.6980 \mathrm{~g} \\
\mathrm{~S}_{\mathrm{o}}=\mathrm{nr}^{2}= \\
5.3066 \mathrm{~cm}^{2} \\
\text { Boric acid }\end{array}$ \\
\hline
\end{tabular}

Table 4. Magisterial formulae prepared with a conventional technique (in a mortar). Viscous elasticity of the formulae $\left(\mathrm{S}_{\mathrm{t}}-\mathrm{S}_{\mathrm{o}}\right.$, $\left.\mathrm{cm}^{2}\right)$ presented as mean values from $3-5$ measurements at $25.0 \pm 0.1^{\circ} \mathrm{C}$

\begin{tabular}{|c|c|c|c|c|c|c|c|c|}
\hline No. & $\underset{(\min )}{\mathrm{t}}$ & $\begin{array}{c}m_{t}-m_{0} \\
(g)\end{array}$ & $\begin{array}{l}\text { No. } 1 \text { "u" } \\
\mathrm{S}_{\mathrm{t}}-\mathrm{S}_{\mathrm{o}} \\
\left(\mathrm{cm}^{2}\right)\end{array}$ & $\begin{array}{l}\text { No. } 2 \text { "u" } \\
\mathrm{S}_{\mathrm{t}}-\mathrm{S}_{\mathrm{o}} \\
\left(\mathrm{cm}^{2}\right)\end{array}$ & $\begin{array}{l}\text { No. } 3 \text { "u" } \\
\mathrm{S}_{\mathrm{t}}-\mathrm{S}_{\mathrm{o}} \\
\left(\mathrm{cm}^{2}\right)\end{array}$ & $\begin{array}{l}\text { No. } 4 \text { "u" } \\
\mathrm{S}_{\mathrm{t}}-\mathrm{S}_{\mathrm{o}} \\
\left(\mathrm{cm}^{2}\right)\end{array}$ & $\begin{array}{l}\text { No. } 5 \text { "u" } \\
\mathrm{S}_{\mathrm{t}}-\mathrm{S}_{\mathrm{o}} \\
\left(\mathrm{cm}^{2}\right)\end{array}$ & $\begin{array}{l}\text { No. 6 "u" } \\
\mathrm{S}_{\mathrm{t}}-\mathrm{S}_{\mathrm{o}} \\
\left(\mathrm{cm}^{2}\right)\end{array}$ \\
\hline 1 & 15 & 20 & 1.6957 & 2.7869 & 0.5947 & 0.0743 & 1.0499 & 0.6888 \\
\hline 2 & 30 & 50 & 4.5040 & 5.2988 & 0.8007 & 0.2296 & 1.4973 & 0.9263 \\
\hline 3 & 45 & 100 & 8.7430 & 8.7920 & 2.3531 & 1.1874 & 2.4393 & 2.1724 \\
\hline 4 & 60 & 200 & 14.4028 & 13.9200 & 5.1810 & 2.2078 & 4.5117 & 4.0820 \\
\hline 5 & 75 & 300 & 19.3895 & 17.8600 & 6.3272 & 4.1448 & 6.2309 & 6.1838 \\
\hline 6 & 90 & 400 & 23.3145 & 23.1045 & 7.5360 & 4.7336 & 8.4151 & 8.4780 \\
\hline & & & $\begin{array}{c}\mathrm{m}_{\circ} \text { of a plate } \\
=27.3970 \mathrm{~g} \\
\mathrm{~S}_{\mathrm{o}}=\mathrm{nr}^{2}= \\
9.3434 \mathrm{~cm}^{2} \\
\text { Salicylic acid }\end{array}$ & $\begin{array}{c}\mathrm{m}_{\circ} \text { of a plate } \\
=26.6150 \mathrm{~g} \\
\mathrm{~S}_{\mathrm{o}}=\mathrm{nr}^{2}= \\
8.5486 \mathrm{~cm}^{2} \\
\text { Salicylic acid }\end{array}$ & $\begin{array}{c}\mathrm{m}_{\mathrm{o}} \text { of a plate } \\
=27.0820 \mathrm{~g} \\
\mathrm{~S}_{0}=\mathrm{nr}^{2}= \\
4.7119 \mathrm{~cm}^{2} \\
\text { Salicylic acid }\end{array}$ & $\begin{array}{c}\mathrm{m}_{\circ} \text { of a plate } \\
=26.6630 \mathrm{~g} \\
\mathrm{~S}_{0}=n \mathrm{r}^{2}= \\
6.6018 \mathrm{~cm}^{2} \\
\text { Boric acid }\end{array}$ & $\begin{array}{c}\mathrm{m}_{\circ} \text { of a plate } \\
=27.5620 \mathrm{~g} \\
\mathrm{~S}_{0}=\mathrm{nr}^{2}= \\
5.1045 \mathrm{~cm}^{2} \\
\text { Boric acid }\end{array}$ & $\begin{array}{c}\mathrm{m}_{\mathrm{o}} \text { of a plate } \\
=26.6980 \mathrm{~g} \\
\mathrm{~S}_{0}=n \mathrm{r}^{2}= \\
6.3762 \mathrm{~cm}^{2} \\
\text { Boric acid }\end{array}$ \\
\hline
\end{tabular}


Table 5. Correlation equations describing a relationship between an increase in the surface area of an ointment, i.e. its viscous elasticity $(\Delta \mathrm{S})$ and applied strain $(\Delta \mathrm{m}): \Delta \mathrm{S}-\mathrm{f}(\Delta \mathrm{m})$

\begin{tabular}{|c|c|c|c|c|c|c|c|c|}
\hline \multirow{2}{*}{$\begin{array}{c}\text { Magisterial } \\
\text { formulae }\end{array}$} & \multicolumn{4}{|c|}{ Unguator technique } & \multicolumn{4}{|c|}{ Conventional technique } \\
\hline & Type of equation & $r$ & $a \pm d b$ & $\mathrm{~b} \pm \mathrm{db} ; \mathrm{k}$ & Type of equation & $r$ & $a \pm d a$ & $\mathrm{~b} \pm \mathrm{db} ; \mathrm{k}$ \\
\hline No. 1 & $\begin{array}{l}y=a+b \cdot \log a \\
\log y=a+b \cdot 1 / x\end{array}$ & $\begin{array}{l}0.9972 \\
0.9950\end{array}$ & $\begin{array}{l}-49005 \pm 1.0013 \\
0.9900 \pm 0.0535\end{array}$ & $\begin{array}{c}-5.9354 \pm 0.2811 \\
-10.7855 \pm 1.2411\end{array}$ & $\begin{array}{l}y=a+b \cdot x \\
\log y=a+b \cdot \log x\end{array}$ & $\begin{array}{l}0.9922 \\
0.9956\end{array}$ & $\begin{array}{c}2.1074 \pm 2.0249 \\
-0.8297 \pm 0.2811\end{array}$ & $\begin{array}{l}0.0548 \pm 0.0078 \\
0.8552 \pm 0.0918\end{array}$ \\
\hline No. 2 & $\begin{array}{l}y=a+b \cdot x \\
\log y=a+b \cdot \log x\end{array}$ & $\begin{array}{l}0.9950 \\
0.9563\end{array}$ & $\begin{array}{c}1.0918 \pm 0.7014 \\
-7.3610 \pm 4.0138\end{array}$ & $\begin{array}{c}9.0356 \pm 0.0409 \\
-7.0065 \pm 2.4621\end{array}$ & $\begin{array}{l}y=a+b \cdot x \\
\log y=a+b \cdot \log x\end{array}$ & $\begin{array}{l}0.9955 \\
0.9996\end{array}$ & $\begin{array}{c}2.7542 \pm 1.5335 \\
-0.4593 \pm 0.0541\end{array}$ & $\begin{array}{l}0.0516 \pm 0.0068 \\
0.6969 \pm 0.0255\end{array}$ \\
\hline No. 3 & $\begin{array}{l}y=a+b \cdot \log x \\
\log y=a+b \cdot 1 / x\end{array}$ & $\begin{array}{l}0.9521 \\
0.9627\end{array}$ & $\begin{array}{c}-1.0781 ` \pm 1.2528 \\
0.4737 \pm 0.0958\end{array}$ & $\begin{array}{l}1.7358^{`} \pm 0.6407 \\
-6.8731 \pm 2.2200\end{array}$ & \begin{tabular}{|l}
$y=a+b \cdot x$ \\
$\log y=a+b \cdot \log x$
\end{tabular} & $\begin{array}{l}0.9921 \\
0.9812\end{array}$ & $\begin{array}{c}0.3441 \pm 1.1606 \\
-1.5252 \pm 0.5402\end{array}$ & $\begin{array}{l}0.0193 \pm 0.0051 \\
0.9366 \pm 0.2556\end{array}$ \\
\hline No. 4 & $\begin{array}{l}y=a+b \cdot x \\
\log y=a+b \cdot x\end{array}$ & $\begin{array}{l}0.9888 \\
0.9862\end{array}$ & $\begin{array}{l}-0.1853 \pm 0.6596 \\
-0.3539 \pm 0.1415\end{array}$ & $\begin{array}{l}0.0222 \pm 0.0385 \\
0.0043 \pm 0.0008\end{array}$ & \begin{tabular}{|l}
$y=a+b \cdot x$ \\
$\log y=a+b \cdot \log x$
\end{tabular} & \begin{tabular}{|l|}
0.9808 \\
0.9902
\end{tabular} & $\begin{array}{l}-0.2381 \pm 0.5577 \\
-2.9977 \pm 0.5987\end{array}$ & $\begin{array}{l}0.0013 \pm 0.0002 \\
1.1482 \pm 0.2833\end{array}$ \\
\hline No. 5 & $\begin{array}{l}y=a+b \cdot x \\
\log y=a+b \cdot x\end{array}$ & $\begin{array}{l}0.9929 \\
0.9579\end{array}$ & $\begin{array}{c}9.5272 \cdot 10^{-4} \pm 0.6771 \cdot 10^{-4} \\
-0.1969 \pm 0.2492\end{array}$ & $\begin{array}{c}2.8797 \cdot 10^{-2} \pm 0.3952 \cdot 10^{-2} \\
0.0042 \pm 0.0014\end{array}$ & $\begin{array}{l}y=a+b \cdot x \\
\log y=a+b \cdot \log x\end{array}$ & $\begin{array}{l}0.9994 \\
0.9885\end{array}$ & $\begin{array}{c}0.5686 \pm 0.2111 \\
-0.9730 \pm 0.3183\end{array}$ & $\begin{array}{l}0.0193 \pm 0.0009 \\
0.7104 \pm 0.1506\end{array}$ \\
\hline No. 6 & $\begin{array}{l}y=a+b \cdot x \\
\log y=a+b \cdot x\end{array}$ & $\begin{array}{l}0.9988 \\
0.9821\end{array}$ & $\begin{array}{l}1.4798 \pm 0.3699 \\
0.3111 \pm 0.0976\end{array}$ & $\begin{array}{l}0.0304 \pm 0.0215 \\
0.0025 \pm 0.0056\end{array}$ & $\begin{array}{l}y=a+b \cdot x \\
\log y=a+b \cdot \log x\end{array}$ & $\begin{array}{l}0.9987 \\
0.9859\end{array}$ & $\begin{array}{c}0.0607 \pm 0.0318 \\
-1.4025 \pm 0.4367\end{array}$ & $\begin{array}{l}0.0207 \pm 0.0141 \\
0.8794 \pm 0.2067\end{array}$ \\
\hline
\end{tabular}

Table 6. Diffusion rate of salicylic acid from model magisterial formulae at $25^{\circ} \mathrm{C}$ to agar hydrogel (5\%), determined using a color complex with $\mathrm{Fe}^{3+}$ ions

\begin{tabular}{|c|c|c|c|c|c|c|c|}
\hline \multirow{3}{*}{ No. } & \multirow{3}{*}{$t(\min )$} & \multicolumn{6}{|c|}{$\mathrm{S}=\pi \mathrm{r}^{2}\left[\mathrm{~mm}^{2}\right]$} \\
\hline & & \multicolumn{2}{|c|}{ Formula no. 1} & \multicolumn{2}{|c|}{ Formula no. 2} & \multicolumn{2}{|c|}{ Formula no. 3} \\
\hline & & "u" & "m" & "u" & "m" & "u" & "m" \\
\hline 1. & 15 & 41.728 & 39.099 & 59.568 & 43.268 & 174.158 & 78.148 \\
\hline 2. & 30 & 85.788 & 86.548 & 75.218 & 73.288 & 201.458 & 118.968 \\
\hline 3. & 60 & 130.698 & 127.668 & 108.588 & 98.188 & 246.578 & 173.558 \\
\hline 4. & 90 & 193.978 & 203.658 & 162.008 & 160.248 & 379.498 & 235.598 \\
\hline 5. & 120 & 228.028 & 259.778 & 209.028 & 219.599 & 513.238 & 340.628 \\
\hline 6. & 150 & 257.048 & 378.318 & 295.808 & 272.528 & 540.238 & 424.888 \\
\hline 7. & 180 & 372.469 & 398.416 & 353.148 & 367.778 & 563.608 & 462.898 \\
\hline
\end{tabular}

Lower parameter: $\mathrm{S}_{\mathrm{o}}=111.92 \mathrm{~mm}^{2}$; "u" - formulae prepared with an unguator; "m" - formulae prepared with a conventional technique (mortar)

Table 7. Diffusion rate of salicylic acid from model magisterial formulae to agar hydrogel (5\%), determined using methyl orange

\begin{tabular}{|c|c|c|c|c|c|c|c|}
\hline \multirow{3}{*}{ No. } & \multirow{3}{*}{$t(\min )$} & \multicolumn{6}{|c|}{$\mathrm{S}=n r^{2}\left[\mathrm{~mm}^{2}\right]$} \\
\hline & & \multicolumn{2}{|c|}{ Formula no. 1} & \multicolumn{2}{|c|}{ Formula no. 2} & \multicolumn{2}{|c|}{ Formula no. 3} \\
\hline & & "u" & "m" & "u" & "m" & "u" & "m" \\
\hline 1. & 30 & 23.213 & 46.375 & 14.454 & 36.286 & 70.898 & 84.552 \\
\hline 2. & 60 & 75.954 & 124.390 & 71.128 & 82.817 & 183.531 & 155.593 \\
\hline 3. & 90 & 138.486 & 188.424 & 144.977 & 175.364 & 283.025 & 254.333 \\
\hline 4. & 120 & 195.529 & 266.647 & 220.564 & 219.581 & 326.413 & 349.336 \\
\hline 5. & 150 & 356.212 & 374.404 & 322.342 & 268.719 & 445.194 & 361,981 \\
\hline 6. & 180 & 368.950 & 379.498 & 426.532 & 339.118 & 518.120 & 486.502 \\
\hline 7. & 240 & 474.427 & 417.932 & 463.524 & 476.574 & 578.199 & 602.617 \\
\hline
\end{tabular}

Lower parameter: $\mathrm{S}_{\mathrm{o}}=111.92 \mathrm{~mm}^{2}$; "u" - formulae prepared with an unguator; " $\mathrm{m}$ " - formulae prepared with a conventional technique (mortar)

Table 8. Correlation equations describing a relationship between an increase in the color zone of salicylic acid diffusion area $\left(\Delta \mathrm{S}\right.$, mm $\left.{ }^{2}\right)$ and time of formula's exposure (t, min)

\begin{tabular}{|c|c|c|c|c|c|c|c|c|}
\hline \multirow{2}{*}{$\begin{array}{c}\text { Magisterial } \\
\text { formulae }\end{array}$} & \multicolumn{4}{|c|}{ Unguator technique } & \multicolumn{4}{|c|}{ Conventional technique } \\
\hline & Type of equation & $r$ & $a \pm d a$ & $b \pm d b ; k$ & Type of equation & r & $a \pm d a$ & $b \pm d b ; k$ \\
\hline No. 1 & $\begin{array}{l}y=a+b \cdot x \\
\log y=a+b \cdot \log x\end{array}$ & \begin{tabular}{|l|}
0.9848 \\
0.9935 \\
\end{tabular} & $\begin{array}{c}21.5147 \pm 39.3501 \\
0.6839 \pm 0.2007\end{array}$ & $\begin{array}{l}1.7971 \pm 0.3633 \\
0.8149 \pm 0.1068\end{array}$ & $\begin{array}{l}y=a+b \cdot x \\
\log y=a+b \cdot \log x\end{array}$ & \begin{tabular}{|l|}
0.9914 \\
0.9941 \\
\end{tabular} & $\begin{array}{l}5.4843 \pm 37.0113 \\
0.51676 \pm 0.2165\end{array}$ & $\begin{array}{l}2.2559 \pm 0.3417 \\
0.9243 \pm 0.1152\end{array}$ \\
\hline No. 2 & $\begin{array}{l}y=a+b \cdot x \\
\log y=a+b \cdot x\end{array}$ & \begin{tabular}{|l|}
0.9894 \\
0.9943 \\
\end{tabular} & $\begin{array}{c}14.5832 \pm 32.8411 \\
1.7390 \pm 0.0634\end{array}$ & $\begin{array}{c}1.8004 \pm 0.3032 \\
4.7484 \cdot 10^{-3} \pm 0.5854 \cdot 10^{-3}\end{array}$ & $\begin{array}{l}y=a+b \cdot x \\
\log y=a+b \cdot \log x\end{array}$ & \begin{tabular}{|l|}
0.9895 \\
0.9951 \\
\end{tabular} & $\begin{array}{c}2.6051 \pm 34.3089 \\
0.6167 \pm 0.3135 \\
\end{array}$ & $\begin{array}{l}1.8862 \pm 0.3167 \\
0.8315 \pm 0.1669 \\
\end{array}$ \\
\hline No. 3 & \begin{tabular}{|l|}
$y=a+b \cdot x$ \\
$\log y=a+b \cdot \log x$ \\
\end{tabular} & \begin{tabular}{|l|}
0.9751 \\
0.9639 \\
\end{tabular} & $\begin{array}{c}128.9506 \pm 75.3201 \\
1.5592 \pm 0.3141 \\
\end{array}$ & $\begin{array}{l}2.6606 \pm 0.6953 \\
0.5268 \pm 0.1672 \\
\end{array}$ & $\begin{array}{l}y=a+b \cdot x \\
\log y=a+b \cdot \log x\end{array}$ & \begin{tabular}{|l|}
0.9948 \\
0.9904 \\
\end{tabular} & \begin{tabular}{|c|}
$37.8176 \pm 31.0108$ \\
$0.9980 \pm 0.2206$ \\
\end{tabular} & $\begin{array}{l}2.4341 \pm 0.2863 \\
0.7304 \pm 0.1179 \\
\end{array}$ \\
\hline No. 1 & \begin{tabular}{|l|}
$y=a+b \cdot x$ \\
$\log y=a+b \cdot \log x$
\end{tabular} & \begin{tabular}{|l|}
0.9825 \\
0.9924 \\
\end{tabular} & $\begin{array}{c}-51.8185 \pm 70.4812 \\
-0.8009 \pm 0.4221 \\
\end{array}$ & $\begin{array}{l}2.2936 \pm 0.4992 \\
1.4950 \pm 0.2123 \\
\end{array}$ & $\begin{array}{l}y=a+b \cdot x \\
\log y=a+b \cdot \log x\end{array}$ & \begin{tabular}{|l|}
0.9584 \\
0.9839 \\
\end{tabular} & \begin{tabular}{|c|}
$22.4342 \pm 91.0294$ \\
$0.1028 \pm 0.4674$ \\
\end{tabular} & $\begin{array}{l}1.8857 \pm 0.6448 \\
1.1004 \pm 0.2297 \\
\end{array}$ \\
\hline No. 2 & $\begin{array}{l}y=a+b \cdot x \\
\log y=a+b \cdot \log x\end{array}$ & \begin{tabular}{|l|}
0.9818 \\
0.9857 \\
\end{tabular} & $\begin{array}{c}-54.8826 \pm 73.9004 \\
-1.2604 \pm 0.6851 \\
\end{array}$ & $\begin{array}{l}2.3536 \pm 0.5234 \\
1.7123 \pm 0.3367 \\
\end{array}$ & $\begin{array}{l}y=a+b \cdot x \\
\log y=a+b \cdot \log x\end{array}$ & \begin{tabular}{|l|}
0.9972 \\
0.9955 \\
\end{tabular} & \begin{tabular}{|c|}
$-30.1578 \pm 25.0443$ \\
$-0.2602 \pm 0.2772$ \\
\end{tabular} & $\begin{array}{l}2.0799 \pm 0.1774 \\
1.2427 \pm 0.1363 \\
\end{array}$ \\
\hline No. 3 & \begin{tabular}{|l|}
$y=a+b \cdot x$ \\
$\log y=a+b \cdot \log x$
\end{tabular} & \begin{tabular}{|l|}
0.9806 \\
0.9880 \\
\end{tabular} & $\begin{array}{c}-36.0566 \pm 80.1209 \\
0.4091 \pm 0.3715 \\
\end{array}$ & $\begin{array}{l}2.2746 \pm 0.5675 \\
1.0171 \pm 0.1823 \\
\end{array}$ & $\begin{array}{l}y=a+b \cdot x \\
\log y=a+b \cdot \log x\end{array}$ & \begin{tabular}{|l|}
0.9926 \\
0.9958 \\
\end{tabular} & \begin{tabular}{|c|}
$19.0146 \pm 49.0378$ \\
$0.5133 \pm 0.2044$ \\
\end{tabular} & $\begin{array}{l}2.4848 \pm 0.3474 \\
0.9575 \pm 0.1005 \\
\end{array}$ \\
\hline
\end{tabular}

Color complex with $\mathrm{Fe}^{3+}$ 2) Change of index coloration induced by $\mathrm{pH}_{\mathrm{aH}+}$ 
Table 9. Rate of volatile component (water) loss from magisterial formulae containing $3 \%$ solution of boric acid, prepared with an aid of an unguator $(\mathrm{u})$ and with a conventional technique in a mortar $(\mathrm{m})$ at $37^{\circ} \mathrm{C} \pm 0.1^{\circ} \mathrm{C}$

\begin{tabular}{|c|c|c|c|c|c|c|c|c|c|c|c|c|c|}
\hline \multirow{2}{*}{ No. } & \multirow{2}{*}{$t(\min )$} & \multicolumn{2}{|c|}{ Formula no. 1 ; u } & \multicolumn{2}{|c|}{ Formula no. 2 ; u } & \multicolumn{2}{|c|}{ Formula no. 3 ; u } & \multicolumn{2}{|c|}{ Formula no. $1 ; \mathrm{m}$} & \multicolumn{2}{|c|}{ Formula no. $2 ; \mathrm{m}$} & \multicolumn{2}{|c|}{ Formula no. $3 ; \mathrm{m}$} \\
\hline & & $\mathrm{m}_{\mathrm{t}}$ & $\begin{array}{c}\% \text { water } \\
\text { loss }\end{array}$ & $\mathrm{m}_{\mathrm{t}}$ & $\begin{array}{c}\% \text { water } \\
\text { loss }\end{array}$ & $\mathrm{m}_{\mathrm{t}}$ & $\begin{array}{c}\% \text { water } \\
\text { loss }\end{array}$ & $\mathrm{m}_{\mathrm{t}}$ & $\begin{array}{c}\% \text { water } \\
\text { loss }\end{array}$ & $\mathrm{m}_{\mathrm{t}}$ & $\begin{array}{c}\% \text { water } \\
\text { loss }\end{array}$ & $\mathrm{m}_{\mathrm{t}}$ & \begin{tabular}{|c}
$\begin{array}{c}\% \text { water } \\
\text { loss }\end{array}$ \\
\end{tabular} \\
\hline 1. & $0 *$ / & 10.9397 & - & 8.8454 & - & 10.1217 & - & 7.0109 & - & 8.6924 & - & 9.7829 & - \\
\hline 2. & 30 & 10.8925 & 0.4314 & 8.8176 & 0.3142 & 10.0679 & 0.5315 & 6.9740 & 0.5263 & 8.5678 & 1.4334 & 9.7115 & 0.7298 \\
\hline 3. & 60 & 10.8739 & 0.6014 & 8.8073 & 0.4307 & 10.0445 & 0.7627 & 6.9577 & 0.7588 & 8.5423 & 1.7267 & 9.6956 & 0.8923 \\
\hline 4. & 90 & 10.8508 & 0.8126 & 8.7927 & 0.5957 & 10.0089 & 0.9958 & 6.9494 & 0.8772 & 8.5308 & 1.8591 & 9.6923 & 0.9261 \\
\hline 5. & 120 & 10.8415 & 0.8976 & 8.7883 & 0.6455 & 10.0089 & 1.1144 & 6.9408 & 0.9998 & 8.5186 & 1.9994 & 9.6696 & 1.1581 \\
\hline 6. & 150 & 10.8303 & 1.002 & 8.7868 & 0.6625 & 9.9835 & 1.3654 & 6.9340 & 1.0968 & 8.5070 & 2.1329 & 9.6651 & 1.2041 \\
\hline 7. & 180 & 10.8227 & 1.0695 & 8.7828 & 0.7077 & 9.9652 & 1.5462 & 6.9294 & 1.1624 & 8.4904 & 2.3239 & 9.6584 & 1.2726 \\
\hline
\end{tabular}

Table 10. Correlation equations describing a rate of volatile component (water) loss from magisterial formulae containing $3 \%$ solution of boric acid at $\mathrm{p}=0.05$

\begin{tabular}{|c|l|c|c|c|c|c|c|c|}
\hline \multirow{2}{*}{$\begin{array}{c}\text { Magisterial } \\
\text { formulae }\end{array}$} & \multicolumn{4}{|c|}{ Unguator technique } & \multicolumn{3}{c|}{ Conventional technique } \\
\cline { 2 - 9 } & Type of equation & $\mathrm{r}$ & $\mathrm{a} \pm \mathrm{db}$ & $\mathrm{b} \pm \mathrm{db} ; \mathrm{k}$ & Type of equation & $\mathrm{r}$ & $\mathrm{a} \pm \mathrm{da}$ \\
\hline \multirow{2}{*}{ No. 4} & $\mathrm{y}=\mathrm{a}+\mathrm{b} \cdot \log \mathrm{x}$ & 0.9928 & $-0.8422 \pm 0.2766$ & $0.8417 \pm 0.1404$ & $\mathrm{y}=\mathrm{a}+\mathrm{b} \cdot \log \mathrm{x}$ & 0.9978 & $-0.6922 \pm 0.1469$ & $0.8169 \pm 0.0745$ \\
& $\log \mathrm{y}=\mathrm{a}+\mathrm{b} \cdot \log \mathrm{x}$ & 0.9956 & $-1.1317 \pm 0.1336$ & $0.5202 \pm 0.0678$ & $\log \mathrm{y}=\mathrm{a}+\mathrm{b} \cdot \log \mathrm{c}$ & 0.9972 & $-0.9185 \pm 0.0957$ & $0.4404 \pm 0.0459$ \\
\hline \multirow{2}{*}{ No. 5} & $\mathrm{y}=\mathrm{a}+\mathrm{b} \cdot \log \mathrm{x}$ & 0.9856 & $-0.4685 \pm 0.2461$ & $0.5262 \pm 0.1249$ & $\mathrm{y}=\mathrm{a}+\mathrm{b} \cdot \log \mathrm{x}$ & 0.9853 & $-0.1861 \pm 0.5081$ & $1.0743 \pm 0.2578$ \\
& $\log \mathrm{y}=\mathrm{a}+\mathrm{b} \cdot \log \mathrm{x}$ & 0.9821 & $-1.1850 \pm 0.2458$ & $0.4691 \pm 0.1247$ & $\log \mathrm{y}=\mathrm{a}+\mathrm{b} \cdot \log \mathrm{c}$ & 0.9940 & $-0.2232 \pm 0.0767$ & $0.2558 \pm 0.0389$ \\
\hline \multirow{2}{*}{ No. 6} & $\mathrm{y}=\mathrm{a}+\mathrm{b} \cdot \mathrm{x}$ & 0.9971 & $0.3526 \pm 0.0825$ & $6.666 \cdot 10^{3} \pm 0.7063 \cdot 10^{3}$ & $\mathrm{y}=\mathrm{a}+\mathrm{b} \cdot \mathrm{x}$ & 0.9770 & $0.6423 \pm 0.1307$ & $3.6965 \cdot 10^{3} \pm 1.1189 \cdot 10^{3}$ \\
& $\log \mathrm{y}=\mathrm{a}+\mathrm{b} \cdot \log \mathrm{x}$ & 0.9964 & $-1.1571 \pm 0.1375$ & $0.5904 \pm 0.0697$ & $\log \mathrm{y}=\mathrm{a}+\mathrm{b} \cdot \log \mathrm{c}$ & 0.9871 & $-0.6148 \pm 0.1889$ & $0.3172 \pm 0.0958$ \\
\hline
\end{tabular}

\section{CONCLUSIONS}

1. Ointments prepared with the aid of an unguator, irrespective of the composition, result in a higher diffusion coefficient than do ointments prepared by means of a conventional technique (in a mortar).

2. Ointments containing salicylic acid that were prepared through the classical method have better viscous elasticity than do ointments prepared in unguator.

3. Ointments containing anhydrous lanolin are characterized by the same viscous elasticity, regardless of the technology used.

4. The method of agar plates with marker makes it possible to estimate the transfer rate of active substance from the drug form.

5. Ointment containing 3\% solution of boric acid have a stable viscosity. This results in a stable value of diffusion coefficient " $D$ ", thus a steady and effective clinical release of a medicinal product.

\section{ACKNOWLEDGE}

The research project with a registration number 503/3-02102/503-31-002 reported here was financed by the Medical University of Lodz (within the framework of the statutory).

\section{REFERENCES}

1. Barlow T., Wiechers J.W.: Measuring Skin hydration. CosmeticsToiletries, 114, 47 (1999).

2. Compas P.M.M., Eccleston G.M.: Vitamin A SKIN PENETRATION. Cosmetics-Toiletries, 113, 69, 1998.

3. Fedors R.F.: A method for estimating both the solubility parameters and molar volumes of liquids. Polymer Eng Sci., 14, 147 (1974).

4. Górecki M.: Reologia farmaceutyczna - perspektywy rozwoju. Farm Pol., 52, 739 (1996).

5. Kasperek R.: Czynniki wpływające na process uwalniania substancji leczniczej z postaci leku warunkujące dostępność farmaceutyczną. Farm Pol., 70/2, 105 (2014)
6. Kołodziejska J.: The effect of saccharic alcohols on rheological parameters of dental anti-inflammatory gels and on pharmaceutical availability of sodium ibuprofen. Acta Pol Pharm., 63, 127- (2006).

7. Korhonen M. et al.: Rheological properties of three component creams containing sorbitan monoesters as surefactants. Int J Pharm., 247, 103 (2002).

8. Krasowska H.: Skóra jako droga podania leku. Farm Pol., 10, 561 (1987).

9. Lindenberg M., Kopp S., Dressman J.B.: Classification of orally administrated drugs on the World Health Organization Model list Essential Medicines according to the biopharmaceutics classification system. Eur J Pharm Biopharm. , 58, 265 (2004).

10. Maciejewska A., Kwiecień M., Figiel W., Tal-Figiel B.: Nowe aspekty wytwarzania maści recepturowych. Farm Pol., 68/6, 365 (2012)

11. Maciejewska A., Niwiński K., Jachowicz R.: Nowe rozwiązania w zakresie sporządzania leku recepturowego - czopki. Farm Pol., 66/12, 823 (2010)

12. Marszałł L.: Techniki i procedury w recepturze aptecznej. Biul. Inform., PKOIA 89, 19, 2008.

13. Mitragotri S.: A theoretical analysis of permeation of small hydrophobic solutes across the stratum carncum based on scaled particle theory. J Pharm Sci., 91, 744 (2002).

14. Morizot F., Le Fur I., Tschachler E.: Sensitive skin. CosmeticsToiletries, 113, 59 (1998).

15. Piechota-Urbańska M., Kołodziejska J., Zgoda M.M.: Viscosity of pharmacopeial multimolecular ointment vehicles and pharmaceutical availability of a model therapeutic agent. Polim Med., 37, 3 (2007).

16. Polish Pharmacopoeia X, 970(2014)

17. Rieger M.M.: The $\mathrm{pH}$ of the stratum corneum and uptake. CosmeticsToiletries, 115, 43 (2000).

18. Rinaki E., Dokumetzidis A., Valsami G., Macheras P.: Identification of biowaivers among Class II drugs: theoretical justification and practical examples. Pharm Res., 21, 1567 (2004).

19. Rosada C., Rodrigues L.M.: Solvent effects in permeation assessed in vivo by skin surface biopsy. BMC Dermatol., 3/5, 1 (2003).

20. Sznitowska M., Janicki S., Ruczyńska E.: Wpływ właściwości fizykochemicznych substancji leczniczych na ich wchłaniania przez skórę. Farm Pol., 5/51, 185 (1995).

21. Sznitowska M., Janicki S.: Promotory wchłaniania substancji leczniczych przez skórę. Farm Pol., 7, 391 (1991). 
The influence of the viscosity of the ointment vehicles magisterial topical preparations, on the speed transfer of biologically active substances

22. Walker R.B., Smith E.W.: The role of percutaneous penetration enhancers. Adv Drug Deliv Rev., 18, 295 (1996).
23. Zgoda M.M., Musiał B., Iwańczyk M.: Wpływ właściwości podłoży hydrożelowych na szybkość dyfuzji niesteroidowych leków przeciwzapalnych do kompartmentu zewnętrznego w warunkach in vitro. Farm Pol., 59, 795 (2003). 